\title{
The effect of fear of progression on quality of life among breast cancer patients: the mediating role of social support
}

\author{
Yue Ban, Mengyao Li, Mingli Yu and Hui Wu* (0)
}

\begin{abstract}
Background: Women with breast cancer are prone to have mental stress and be stimulated by the fear of progression (FOP), then giving rise to a lower quality of life (QOL). The study aimed to examine the relationships between FOP, social support and QOL, and further explore whether social support mediates the association between FOP and QOL among Chinese patients with breast cancer.

Methods: The cross-sectional study was conducted from October 2019 to May 2020 at Anshan Cancer Hospital in Liaoning, China. 244 female breast cancer patients completed questionnaires including the Functional Assessment of Cancer Therapy for Breast (FACT-B), Multi-Dimensional Scale of Perceived Social Support (MSPSS), and Fear of Progression (FOP). Hierarchical multiple regression analysis was performed to assess the associations between FOP, social support and QOL. Asymptotic and resampling strategies were used to explore the mediating role of social support.
\end{abstract}

Results: The mean QOL score was $90.6 \pm 17.0$ among the patients with breast cancer. FOP was negatively correlated with $\mathrm{QOL}$, while social support was positively related to QOL. Social support partly mediated the association between FOP and QOL, and the proportion of the mediating effect accounted for by social support was $25 \%$.

Conclusions: Chinese breast cancer patients expressed low QOL. Social support could mediate the association between FOP and QOL. Medical staffs and cancer caregivers should alleviate patients' FOP to improve their QOL by facilitating social support.

Keywords: Breast cancer, Quality of life, Fear of progression, Social support

\section{Background}

Breast cancer is one of the most common and fatal diseases in the female population, which has a great impact on the psychological, emotional, social and family life of breast cancer patients [1]. In China, the incidence of breast cancer is growing at a rate twice as compared to that of global cancer rate of increase [2]. Besides, female breast cancer showed an escalating trend in years of life lost from 1990 to 2017 [3].The increase of morbidity in

*Correspondence: hwu@cmu.edu.cn

Department of Social Medicine, School of Public Health, China Medical University, No. 77 Puhe Road, Shenyang North New Area, Shenyang 110122, Liaoning, China breast cancer afflicted patients, and aggravation for disease burden put a long-term impact on the psychological health of patients [4]. Simultaneously, psychological distress or emotional changes also have a negative influence on quality of life (QOL), which of the impact is not only confined to the treatment phase but also in the post treatment period [5].

QOL is generally considered to be a multidimensional concept that includes physical, psychological, and social well-being, feelings of health as well as symptoms associated with illness or treatment [6]. It has already been an important indicator which monitors the process of cancer treatment and prognosis or rehabilitation effect in recent years [7]. With the development of medical original author(s) and the source, provide a link to the Creative Commons licence, and indicate if changes were made. The images or other third party material in this article are included in the article's Creative Commons licence, unless indicated otherwise in a credit line to the material. If material is not included in the article's Creative Commons licence and your intended use is not permitted by statutory regulation or exceeds the permitted use, you will need to obtain permission directly from the copyright holder. To view a copy of this licence, visit http://creativecommons.org/licenses/by/4.0/. The Creative Commons Public Domain Dedication waiver (http://creativeco mmons.org/publicdomain/zero/1.0/) applies to the data made available in this article, unless otherwise stated in a credit line to the data. 
technology, the 5-year survival rate of breast cancer patients was as high as $68.1-93.2 \%$ [8]. Even so, due to the pathological and physiological characteristics of cancer itself, the progression or recurrence of cancer has not been effectively solved and prevented [9]. The recurrence rate of breast cancer patients in China was up to 5-30\% [10]. The high recurrence rate may bring psychological stress to patients and impair their QOL [11]. Additionally, Chinese traditional culture stems from interdependent values that emphasize the importance of maintaining prestige and social status [12]. Diagnosis of cancer might potentially affect patients' expression and talk about their fear of cancer. Many patients did not receive adequate psychological support when confronted with the fear of illness progression or recurrence [13]. Furthermore, negative psychological distress and unmet social demands were significantly associated with poor QOL [14]. Consequently, the effect of internal psychological state and external social factors on QOL in breast cancer patients should be given enough attention.

Fear of progression (or recurrence, hereafter FOP) is defined as the fear of the illness progressing or recurring in the same place or in another part of the body [9]. FOP has become an important psychological burden of breast cancer patients, which seriously affects their QOL [15]. Foreign scholars showed that probably $50 \%$ of cancer survivors experience moderate to severe FOP [9]. Moreover, a longitudinal study of QOL for early-stage breast cancer survivors presented that the poorer QOL in women was related to long-term worry about cancer progression [16]. FOP can lead to decrement in physical, mental and social aspects of QOL as well as persist longer after the completion of an active treatment [17]. However, to the best of our knowledge, few studies [15] have examined the relationship between FOP and QOL among female breast cancer patients. Therefore, it is essential to implement relevant research.

Facilitating positive psychosocial outcomes is as crucial as the decreasing negative ones. One of the most effective ways to cope with a traumatic life event is social support [18] which is commonly defined as informational, emotional, and useful assistance provided by one's social network [19]. It played a key role in promoting positive psychological outcomes among breast cancer survivors [20]. The significance of social support has been justified by You et al. that it was successfully used in adjusting to cancer [21]. Surveys of different cancer populations demonstrated that higher social support was linked to better QOL [22, 23]. It was also found social support could alleviate psychosocial distress, thereby holds the potential to serve as a buffer against FOP as well [24]. Additionally, influenced by Chinese Confucian family harmony, Chinese female breast cancer patients would rather prefer to bear the disease pressure alone because of being afraid of bringing a burden to others [25]. Whereas, some scholars indicated that emotional support from family members, which is naturally expected from a closer family members such as spouse and children, have a positive effect on the mental and physical adaptation to the disease [26, 27]. Internal and external positive coping strategies from society or family support are vital for patients to readjust with their surrounding changes [28]. Leung et al. indicated that social support could help patients improve their mental health and enhance their confidence to better cooperate with treatment [29]. Hence, it is necessary to study the role of social support on QOL of breast cancer patients to help alleviate the fear of disease recurrence and pressure of cancer.

Up to now, although the relationships among FOP, social support and QOL have been reported previously [15], the mediating effect of social support between FOP and QOL for Chinese breast cancer patients have not been clearly examined. Social support might be regarded as an important mediating variable in interpersonal relationship, the role mainly relied on individuals' ability to express their needs [30]. Celik et al. found that social support might transform patients' FOP and help them cope with uncertainty, in which way the patients had a better performance in adapting to society and in turn improved their QOL [31]. Walsh assessed the mediating effect of social support by identifying the linkage between distress and QOL for breast cancer patients, the result indicated that social support partially mediated the relation between symptom distress and QOL [32]. The above researches suggested that social support might help cancer patients ease the negative emotions and boost QOL.

Based on the above literature studies, we hypothesized that social support was an important factor in improving QOL. Given that FOP is common among breast cancer patients $[16,17,33]$ and may generate adverse consequences, hence, if social support is a mediator mechanism between FOP and QOL, it will provide significant intervention guidance for buffering the adverse effects of FOP on QOL. In view of the empirical studies above and different cultural context and conditions, the purpose of our study was to verify the following three hypotheses among Chinese female breast cancer patients: 1) FOP has a negative effect on QOL; 2) social support has a positive effect on QOL; 3) social support mediates the association between FOP and QOL.

\section{Methods}

\section{Ethics statement}

The procedures of this study were reviewed and approved by the Committee on Human Experimentation of China Medical University and Anshan cancer hospital in 
Liaoning, China. And the process of study was in accordance with the ethical standards.

Written informed consent for the investigation was obtained from each participant. We protected personal privacy when handling personal data and kept personal records confidential.

\section{Participants and procedure}

A cross-sectional study was conducted from October 2019 to May 2020. All participants were from the Department of Breast Surgery, Anshan Cancer Hospital, Liaoning, China. The inclusion criteria in this study were as follows: (1) Chinese speaking female having age $\geq 18$ years; (2) with pathological diagnosis of breast cancer at any stage of disease; (3) had completed all surgical procedures and continued radiotherapy or chemotherapy; (4) had clear consciousness and cognition. Exclusion criteria were as follows: (1) patients suffered from mental problems or cognitive disorders and intellectual impairments prior to cancer diagnosis; (2) unwilling to be enrolled into the study program. Selfadministered questionnaires were distributed to the patients by researchers and medical staff, which were being given rigorous training beforehand prior the survey. The process of collecting questionnaires had strict quality control measures to avoid possible bias. Eligible patients would sign an informed consent form and filled out the questionnaire in a private place in the inpatient department within one week after surgery. A total of 266 patients had given consent and were enrolled by research staff to assess for eligibility. Twenty-two patients were excluded due to missing values exceeding 10\% (mainly cancer stage and various items of the QOL questionnaire). Finally, 244 breast cancer patients were admitted into the analysis with an effective response rate of $92 \%$.

\section{Demographic and clinical characteristics}

There were six demographic variables and four clinical variables in our study. Age at time of survey was divided into three types: " $\leq 45$ ", " $46-55$ " and " $\geq 56$ " [34]. Residence was divided into two groups: "city" and "rural". Marital status included two groups: "single/separated/ divorced/widow" and "married/cohabitation". Education level was categorized as "middle school or under", "senior high school", "undergraduate or above". Household per capita monthly income (RMB: Yuan) included " $\leq 3000$ ", "3001-4000", "4001-5000" and " $\geq$ 5001" [35]. Principal caregiver comprised spouse, adult children and relatives. Cancer stage were divided into "0-I", "II" and "III+IV".
Others (current recurrence, chemotherapy, radiotherapy) were divided as "yes" and "no" two groups.

\section{Measures \\ Measurement of QOL}

The Chinese simplified version of the FACT-B was used to assess the QOL, which has shown good reliability and validity [36]. It comprised five subscales: physical (seven items), social (seven items), emotional (six items) and functional well-being (seven items) together with the Breast Cancer Subscale (BCS) (nine items). Each item was given on a five-point Likert scale $(0=$ "not at all" to $4=$ "very much"). A total score of QOL was obtained by summing the scores of all five subscales [37]. The total score ranges from 0 to 144 and patients with higher scores suggest better QOL. The Cronbach's alpha coefficient of total scale was 0.879 in present study.

\section{Measurement of the fear of progression}

Fear of progression was measured by the 12-item short version of the Fear of Progression Questionnaire (FOPQ-SF) [38]. And each item was rated on a 5-point Likert scale ranging from 1 "never" to 5 "very often". Higher scores indicate a higher fear of progression. Wu et al. [39] translated it into the Chinese version and had a high internal consistency coefficient (Cronbach's alpha $=0.883$ ). In the current study, the Cronbach's alpha for the total scale was 0.945 .

\section{Measurement of social support}

We chose the Multi-Dimensional Scale of Perceived Social Support (MSPSS), which was measured by using the 12-item version designed from Zimet et al. [40]. The scale comprised three measurements: families and friends support as well as significant others. The gross score of social support was used in current sample. Participants rated each item on a 7-point Likert scale ( 1 = "very strongly disagree" to $7=$ "very strongly agree"). The higher total score indicates better social support. The Chinese version of the scale had been verified adequate reliability and validity among cancer patients [41] and Cronbach's alpha coefficient was 0.965 in our research.

\section{Statistical analysis}

All the analyses were performed by IBM SPSS Statistics 21.0 (IBM, Asia Analytics Shanghai), with a two-tailed $P<0.05$ considered to be statistically significant. Before conducting the data analyses, the normal distribution of the variables was tested by P-P-plot analyses and Kolmogorov-Smirnov tests. The QOL and continuous 
variables fulfilled the postulation of normal distribution in our study $(P>0.05)$. According to demographic and clinical groups, we used t-test and one-way ANOVA analysis to examine group differences of QOL. Pearson's correlation analysis was applied to analyse the correlations among QOL, FOP and social support. Hierarchical multiple regression analysis was conducted to explore social support as a potential mediating role on the association between FOP and QOL. Regression analysis consisted of four steps. In step 1, the age and potential control variables (which were significant variables in univariate analysis) were entered, FOP was entered in step 2 and social support was entered in step 3, FOP and social support simultaneously were entered in step 4 . The variance inflation factor (VIF) values $<10$ were considered to be non-collinear [42].

We used asymptotic and resampling strategies to examine whether social support mediated the association between FOP and QOL [43]. Our study was performed by five thousand bootstrap samples. The selection of control variables was based on the statistical significance of univariate analysis. Total scores for FOP, social support and QOL were standardized separately by subtracting the mean value and dividing by the standard deviation to account for the differences in scale scores. The total effect ("c path"), the direct effect ("c' path") and the indirect effects ("a*b path") were presented. The bias-corrected and accelerated 95\% confidence interval (BCa 95\% CI) for each a*b product was calculated and if a $\mathrm{BCa} 95 \% \mathrm{CI}$ excluded 0 , indicating a significant mediation.

\section{Results}

\section{Descriptive statistics}

Demographic and clinical characteristics of participants and group differences on QOL were shown in Table 1. The average age of the participants was $54.3 \pm 10.5$ (mean \pm SD) and 121 (50\%) of them were above 56 years old. 102 (42\%) of patients had senior high school and 115 (47\%) of patients were cared by relatives. With regard to clinical variables, only 27 (11\%) of the patients had undergone cancer recurrence. Among the six demographic variables, education level and principal caregiver were found to be significantly correlated with QOL, and patients who went senior high school reported higher QOL score than those who went middle school or under and undergraduate or above $(P<0.05)$; and patients cared by different caregivers also showed different levels of QOL $(P<0.05)$. Among the four clinical variables, only whether current recurrence or not was found to be significantly correlated with QOL, and patients who had undergone cancer recurrence reported lower QOL score than those without recurrence $(P<0.05)$.

\section{Correlation between FOP, social support and QOL}

Correlation coefficients between continuous variables were presented in Table 2. The mean QOL score among breast cancer patients was $90.6 \pm 17.0$. FOP was negatively associated with QOL $(r=-0.408, P<0.01)$, social support was positively correlated with QOL $(r=0.472$, $P<0.01)$.

\section{Hierarchical multiple linear regression}

The results of the hierarchical multiple regression were shown in Table 3. FOP and social support totally accounted for $29 \%$ of the variance in QOL. FOP was negatively associated with QOL $(\beta=-0.391, P<0.01$; step 2 ) and social support was positively associated with QOL $(\beta=0.472, P<0.01$; step 3$)$. Moreover, the absolute value of regression coefficient of FOP on QOL diminished from 0.391 to $0.293(\beta=0.293, P<0.01)$ after adding social support in step 4 . The results meant that social support probably mediated the relation between FOP and QOL partially.

\section{Asymptotic and resampling strategies in the mediating role of social support and its path analysis}

The results of the mediation analysis were presented in Table 4. The total effect of FOP on QOL ("c path") was initially evaluated. FOP was negative association with QOL $(c=-0.391, P<0.01)$. Then, the indirect effect of FOP on QOL via social support was observed (path $\mathrm{a}^{*} \mathrm{~b}, \mathrm{a}=-0.244, \mathrm{~b}=0.401, \mathrm{a}$ " $\mathrm{b}(\mathrm{BCa} 95 \% \mathrm{CI})=-0.098$ $(-0.161,-0.038))$. The confidence interval for indirect effect did not contain zero, which suggested that social support played a mediating role between FOP and QOL. Furthermore, when social support was entered to the model as a mediator, the direct effect of FOP on QOL (path $\left.c^{\prime}\right)$ was still significant $\left(c^{\prime}=-0.293, P<0.01\right)$. Hence, social support had a partially mediating effect in the relationship between FOP and QOL for patients in this study. To understand the effect size of the mediating pathway, we calculated the proportion of the total effect of the FOP on QOL that was mediated by social support with the formula $(\mathrm{a} * \mathrm{~b}) / \mathrm{c}$. The proportion of mediation of social support was $25 \%$. The mediating model and path coefficients were shown in Fig. 1.

\section{Discussion}

Our findings showed that the mean score of QOL value was $90.6 \pm 17.0$ in the present study, which was lower compared with the level of QOL $(96.4 \pm 17.7)$ reported in Eastern China among female patients with breast cancer [44]. Moreover, the mean score of QOL value was much lower than that of patients with breast cancer in other developed countries. Milbury et al. reported that the mean score of QOL was 104.12 \pm 14.77 in USA during 
Table 1 Demographic and clinical characteristics and the score of QOL among breast cancer patients

\begin{tabular}{|c|c|c|c|c|c|}
\hline \multirow[t]{2}{*}{ Variables } & \multirow[t]{2}{*}{$\mathrm{N}(\%)$} & \multicolumn{4}{|l|}{ QOL } \\
\hline & & Mean & SD & $F / t$ & $P$-value \\
\hline Age & & & & 2.739 & 0.067 \\
\hline$\leq 45$ & $47(19)$ & 91.7 & 18.0 & & \\
\hline $46-55$ & $76(31)$ & 86.8 & 16.1 & & \\
\hline$\geq 56$ & $121(50)$ & 92.5 & 16.8 & & \\
\hline Residence & & & & -0.103 & 0.918 \\
\hline City & $192(79)$ & 90.5 & 17.1 & & \\
\hline Rural & $52(21)$ & 90.8 & 16.6 & & \\
\hline Marital status & & & & 1.700 & 0.090 \\
\hline Married/cohabitation & $224(92)$ & 91.1 & 16.7 & & \\
\hline Single/divorced/Separated/widow & $19(8)$ & 84.4 & 18.5 & & \\
\hline Education level & & & & 3.186 & 0.043 \\
\hline Middle school or under & $86(35)$ & 91.8 & 17.1 & & \\
\hline Senior high school & $102(42)$ & 92.2 & 16.2 & & \\
\hline Undergraduate or above & $56(23)$ & 85.6 & 17.5 & & \\
\hline Income (Yuan per Month) & & & & 1.671 & 0.174 \\
\hline$\leq 3000$ & $78(32)$ & 90.9 & 19.0 & & \\
\hline $3001-4000$ & $88(36)$ & 92.4 & 16.5 & & \\
\hline $4001-5000$ & $29(12)$ & 91.9 & 14.2 & & \\
\hline$\geq 5001$ & $49(20)$ & 85.9 & 15.5 & & \\
\hline Principal caregiver & & & & 4.804 & 0.009 \\
\hline Spouse & $53(22)$ & 90.7 & 18.4 & & \\
\hline Adult children & $76(31)$ & 95.1 & 15.2 & & \\
\hline Relatives & $115(47)$ & 87.8 & 16.8 & & \\
\hline Current recurrence & & & & -2.580 & 0.01 \\
\hline Yes & $27(11)$ & 82.7 & 14.3 & & \\
\hline No & $217(89)$ & 91.5 & 17.0 & & \\
\hline Cancer stage & & & & 0.074 & 0.929 \\
\hline $0-1$ & $61(25)$ & 91.3 & 17.1 & & \\
\hline$\|$ & $109(45)$ & 90.32 & 17.0 & & \\
\hline$I I I+I V$ & $74(30)$ & 90.3 & 17.1 & & \\
\hline Chemotherapy & & & & -0.316 & 0.752 \\
\hline Yes & $159(65)$ & 90.3 & 16.9 & & \\
\hline No & $85(35)$ & 91.0 & 17.2 & & \\
\hline Radiotherapy & & & & -1.859 & 0.064 \\
\hline Yes & $98(40)$ & 88.1 & 15.9 & & \\
\hline No & $146(60)$ & 92.5 & 17.5 & & \\
\hline
\end{tabular}

Table 2 Correlation between FOP, social support and QOL

\begin{tabular}{lrrlll}
\hline Variables & Mean & SD & QOL & FOP & Social support \\
\hline QOL & 90.6 & 17.0 & - & & \\
FOP & 37.8 & 8.8 & $-0.408^{* *}$ & - & \\
Social support & 60.6 & 11.8 & $0.472^{* *}$ & $-0.239^{* *}$ & - \\
\hline$* *_{0}<01$ & & & & &
\end{tabular}

the year 2017 [45], Matthies et al. reported a mean QOL score of $102.66 \pm 22$ in Germany during the year 2019 [46]. However, the mean QOL score observed in our investigation was closer to the Asian situation-the mean score of QOL in Korea was $91.26 \pm 20.08$ as reported by Park et al. in 2019 [47]. QOL in the current study was at a lower level in its individual capacity possibly because of three reasons. Firstly, although there is continuous improvement in diagnosis and treatment technology and it is more convenient to obtain quality care in China, the psychological fear brought by the cancer itself and unmet inner needs of patients have not been received adequate attention by nursing staff and family members [48]. Secondly, Chinese cultural philosophies shape individual 
Table 3 Hierarchical multiple regression results of QOL among breast cancer patients

\begin{tabular}{|c|c|c|c|c|c|c|c|c|c|c|c|c|}
\hline \multirow[t]{3}{*}{ Variables } & \multicolumn{12}{|l|}{ QOL } \\
\hline & \multicolumn{3}{|l|}{ Step 1} & \multicolumn{3}{|l|}{ Step 2} & \multicolumn{3}{|l|}{ Step 3} & \multicolumn{3}{|l|}{ Step 4} \\
\hline & $\beta$ & $S D$ & $P$-value & $\beta$ & $S D$ & $P$-value & $\beta$ & $S D$ & $P$-value & $\beta$ & $S D$ & $P$-value \\
\hline Constant & 81.898 & & & 108.867 & & & 39.780 & & & 66.336 & & \\
\hline \multicolumn{13}{|l|}{ Age } \\
\hline$\leq 45$ & 0 & - & - & 0 & - & - & 0 & - & - & 0 & - & - \\
\hline $46-55$ & -0.170 & 0.464 & 0.047 & -0.165 & 0.464 & 0.036 & -0.134 & 0.464 & 0.074 & -0.136 & 0.464 & 0.056 \\
\hline$\geq 56$ & -0.133 & 0.501 & 0.165 & -0.138 & 0.501 & 0117 & -0.093 & 0.501 & 0.272 & -0.102 & 0.501 & 0.200 \\
\hline \multicolumn{13}{|l|}{ Education level } \\
\hline Middle school or under & 0 & - & - & 0 & - & - & 0 & - & - & 0 & - & - \\
\hline Senior high school & 0.018 & 0.494 & 0.803 & 0.087 & 0.494 & 0.185 & 0.002 & 0.494 & 0.976 & 0.056 & 0.494 & 0.343 \\
\hline Undergraduate or above & -0.115 & 0.421 & 0.127 & -0.044 & 0.421 & 0.532 & -0.100 & 0.421 & 0.132 & -0.049 & 0.421 & 0.441 \\
\hline \multicolumn{13}{|l|}{ Principal caregiver } \\
\hline Spouse & 0 & - & - & 0 & - & - & 0 & - & - & 0 & - & - \\
\hline Adult children & 0.095 & 0.464 & 0.261 & 0.098 & 0.464 & 0.210 & 0.197 & 0.464 & 0.009 & 0.183 & 0.464 & 0.011 \\
\hline Relatives & -0.101 & 0.500 & 0.216 & -0.060 & 0.500 & 0.430 & 0.007 & 0.500 & 0.927 & 0.022 & 0.500 & 0.752 \\
\hline \multicolumn{13}{|l|}{ Current recurrence } \\
\hline Yes & 0.139 & 0.314 & 0.028 & 0.132 & 0.314 & 0.023 & $0.110^{*}$ & 0.314 & 0.047 & 0.109 & 0.314 & 0.037 \\
\hline No & 0 & - & - & 0 & - & - & 0 & - & - & 0 & - & - \\
\hline FOP & 0 & - & - & -0.391 & 8.758 & 0.000 & 0 & - & - & -0.293 & 8.758 & 0.000 \\
\hline Social support & 0 & - & - & 0 & - & - & 0.472 & 11.769 & 0.000 & 0 & - & - \\
\hline Social support & 0 & - & - & 0 & - & - & 0 & - & - & 0.401 & 11.769 & 0.000 \\
\hline$F$ & 3.238 & & 0.003 & 8.891 & & 0.000 & 12.594 & & 0.000 & 15.709 & & 0.000 \\
\hline Adjusted $R^{2}$ & 0.061 & & & 0.206 & & & 0.276 & & & 0.353 & & \\
\hline$\Delta R^{2}$ & 0.088 & & & 0.145 & & & 0.212 & & & 0.144 & & \\
\hline
\end{tabular}

Table 4 The results of the mediation analysis

\begin{tabular}{lcll}
\hline Mediation path & Coefficient & $\boldsymbol{P}$-value & BCa 95\% Cl \\
\hline$c$ & -0.391 & $<0.01$ & $(-0.506,-0.275)$ \\
$a$ & -0.244 & $<0.01$ & $(-0.369,-0.119)$ \\
$b$ & 0.401 & $<0.01$ & $(0.293,0.508)$ \\
$a^{*} b$ & -0.098 & - & $(-0.161,-0.038)$ \\
$c^{\prime}$ & -0.293 & $<0.01$ & $(-0.401,-0.185)$ \\
\hline
\end{tabular}

BCa 95\% Cl: the bias-corrected and accelerated 95\% confidence interval; age education level, principal caregiver and current recurrence were covariates

perceptions of disease, which are completely different from western cultural foundations. Influenced by traditional introvert culture, Chinese people are unwilling to share their feelings and thoughts with others, especially regarding disease-related issues [49]. As a result, some emotional pressure cannot be released contributing to psychological disorders of Chinese female breast cancer patients. Particularly, surgery and relevant treatments (changes in sexual function and self-image) affect an individual's physiology, psychology and social-relations [50],

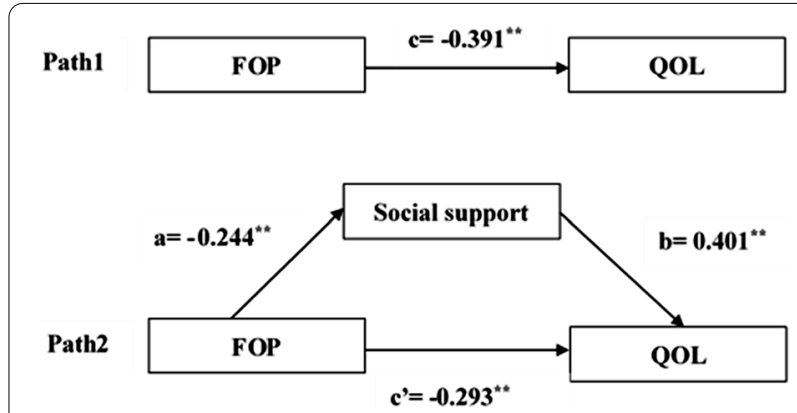

Fig. 1 Model of the mediating role of Social support between FOP and QOL. Note: ${ }^{* *} P<0.01$

thus promoting a lower QOL. Finally, subsistent medical institutions cannot offer targeted professional consultation to cancer patients in China, especially patients with recurrence, which is one of the most frustrating and difficult phase for cancer patients. Karam proposed that most recurrences are symptomatic (e.g. chest pain, cough, dyspnea, and so on) and occur during the interval 
between scheduled visits [51]. Relapsed patients had a higher sense of fear of progression at reexamination time, together with disturbing thoughts, anxiety and poor QOL [52]. By contrast, psychological counseling and supportive care are widely popularized in western countries [53]. The above-mentioned conditions collectively intensified the negative impact on patients, which led to the poorer QOL of breast cancer patients.

Furthermore, the associations between FOP, social support and QOL of breast cancer patients were explored in our study. We found that FOP was negatively associated with QOL. Gotze et al. demonstrated that the FOP was associated with reduced emotional and social domains on QOL [54]. Socio-demographic, psychosocial and clinical characteristics, such as age, living with a spouse, social support and poorer health conditions were important determinants of FOP [55]. Gallenkamp et al. indicated that female survivors who were in five to seven years post-diagnosis, being socially isolated and those having less education or recurrence were at a greater risk to experience moderate or high levels of FOP [24]. These factors had an impact on the QOL, reducing life expectancy as well. What is more, our results indicated that social support positively correlated with QOL among patients with breast cancer. Cancer patients revealed higher QOL and lower depression when they received more social support [56]. Besides, in close relationships, women's adaptation to breast cancer and family expression patterns significantly affect patients' ability to cope with the disease [57]. Lim et al. quoted that effective communication and support contributed to a higher QOL [58]. As a consequence, medical staff and family caregivers must be aware of the importance of providing social support to breast cancer patients.

As expected, the result showed that social support acted as a mediator in the relation between FOP and QOL among Chinese breast cancer patients. A higher level of FOP might be alleviated by the higher level of social support and further led to the higher level of QOL. Social support (as a positive factor) weakened the negative impact of FOP (as a risk factor) on QOL. In brief, social support played a significant role in patients' health outcomes including health-related quality of life [29]. It meant we could improve the QOL of breast cancer patients via promoting the level of social support and reducing the sense of fear of disease. For this purpose, designing intervention programs via enhancing social support is an effective way to eventually achieve the goal of prolonging life expectancy and improving QOL. A supportive-expressive intervention program developed by the Stanford university laboratory proposed a kind of intervention model including social support which is mainly focused on encouraging emotional expression, arranging life priorities, dealing with a fear of death, cultivating relationships with families and friends, and increasing the adaptability to cope with a traumatic event and eventually improve the QOL [59]. Kissane et al. using this intervention model on Australian patients with metastatic breast cancer, evidenced that the effectiveness of this model in improving QOL and suppress depressive emotions was significant [60]. Therefore, future studies should be focused on the impact of interventions related to social support on Chinese breast cancer patients.

There were several limitations of our study. Firstly, a cross-sectional design was applied to the present study, so these findings could not be used to construct a formal causality or to identify the direction of causality between psycho-social resources and QOL. They are needed to be validated via longitudinal researches. Secondly, individuals with other types of diseases or variable comorbidities might not be surveyed. Additionally, we only recruited breast cancer patients from a single hospital in Liaoning Province, north of China, which might limit its applicable to other regions due to the cultural differences between North and South China. Thirdly, psychological variables were mainly evaluated using self-report instruments, which might be subject to recall and response bias. Our study tried to minimize the bias by using the QOL, FOP, and MSPSS that have been well validated for application among subjects in China. Finally, our study focused only on the association between FOP, social support and QOL. Further investigation needs to be taken into consideration to explore other social psychology and emotional predictors for the level of QOL in breast cancer patients, such as society, family environment factors and so on.

\section{Conclusions}

In summary, our findings suggested that the QOL of breast cancer patients was generally at a lower level in Liaoning Province, China. Social support partially mediated the relationship between FOP and QOL in breast cancer patients, which was the first attempt to perform the relationship between psycho-social mediating resources and QOL among Chinese breast cancer to our limited knowledge. Present study highly recommended that positive social support would be beneficial to improve the QOL of breast cancer patients. Meanwhile, providing targeted support for the breast cancer patients, such as positive interventions of expressive support, might be helpful to improve their QOL as well as relieve their fear of disease in the oncology field. 


\section{Abbreviations}

QOL: Quality of life; FOP: Fear of progression; MSPSS: Multi-Dimensional Scale of Perceived Social Support; FACT-B: Functional Assessment of Cancer Therapy for Breast.

\section{Acknowledgements}

The authors would acknowledge the services of staffs in the Anshan cancer hospital (Liaoning, China), who helped to get the written informed consent about the conduct of this survey and distribute the questionnaires to the concerned patients.

\section{Authors' contributions}

YB: Data collection and curation, literature survey, drafting initial manuscript. ML: Conceptual design and methodology. MY: Formal analysis. HW: Supervision, project administration, reviewing and editing. The final manuscript was read and approved by all authors. All authors read and approved the final manuscript.

\section{Funding}

This work was supported by National Natural Science Foundation of China [Grant Number: 71904204].

\section{Availability of data and materials}

The datasets used and/or analyzed during the current study are available from the corresponding author on reasonable request.

\section{Declarations}

\section{Ethics approval and consent to participate}

The study was approved by the Committee for Human Trials of China Medical University and each participant took part in the study after providing a written informed consent.

\section{Consent for publication}

Not applicable.

\section{Competing interests}

The authors declare that they have no competing interests.

Received: 27 July 2020 Accepted: 4 July 2021

Published online: 10 July 2021

\section{References}

1. Schmidt ME, Wiskemann J, Steindorf K. Quality of life, problems, and needs of disease-free breast cancer survivors 5 years after diagnosis. Qual Life Res. 2018:27(8):2077-86.

2. Du J. Breast cancer in China. World Latest Med Inf. 2019;19(46):371-2 (article in Chinese)

3. Cen X, Wang D, Sun W, Cao L, Zhang Z, Wang B, et al. The trends of mortality and years of life lost of cancers in urban and rural areas in China, 1990-2017. Cancer Med. 2020;9(4):1562-71.

4. Wang YH, Li JQ, Shi JF, Que JY, Liu JJ, Lappin JM, et al. Depression and anxiety in relation to cancer incidence and mortality: a systematic review and meta-analysis of cohort studies. Mol Psychiatry. 2020;25(7):1487-99.

5. Oh PJ, Cho JR. Changes in fatigue, psychological distress, and quality of life after chemotherapy in women with breast cancer: a prospective study. Cancer Nurs. 2020:43(1):E54-60.

6. Felce D, Perry J. Quality of life: its definition and measurement. Res Dev Disabil. 1995:16(1):51-74.

7. Ferrell BR, Grant M, Funk B, Otis-Green S, Garcia N. Quality of life in breast cancer. Part II: psychological and spiritual well-being. Cancer Nurs. 1998;21(1):1-9.

8. Zeng $\mathrm{H}$, Chen W, Zheng R, Zhang S, Ji JS, Zou X, et al. Changing cancer survival in China during 2003-15: a pooled analysis of 17 populationbased cancer registries. Lancet Glob Health. 2018;6(5):e555-67.
9. Dinkel A, Herschbach P. Fear of progression in cancer patients and survivors. Recent Results Cancer Res. 2018;210:13-33.

10. Liu L, Lin F, Han Y. Meta-analysis of risk factors for postoperative recurrence of breast cancer in Chinese women. Public Health China. 2017;33(1):165-9 (article in Chinese).

11. Koch L, Bertram H, Eberle A, Holleczek B, Schmid-Hopfner S, Waldmann A et al. Fear of recurrence in long-term breast cancer survivors-still an issue. Results on prevalence, determinants, and the association with quality of life and depression from the cancer survivorship - a multi-regional population-based study. Psychooncology. 2014;23(5):547-54.

12. Shang C, Beaver K, Campbell M. Social cultural influences on breast cancer views and breast health practices among Chinese women in the United Kingdom. Cancer Nurs. 2015;38(5):343-50.

13. Sarkar S, Sautier L, Schilling G, Bokemeyer C, Koch U, Mehnert A. Anxiety and fear of cancer recurrence and its association with supportive care needs and health-care service utilization in cancer patients. J Cancer Surviv. 2015;9(4):567-75.

14. Al-Ghabeesh SH, Al-Kalaldah M, Rayan A, Al-Rifai A, Al-Halaiqa F. Psychological distress and quality of life among Jordanian women diagnosed with breast cancer: the role of trait mindfulness. Eur J Cancer Care (Engl). 2019;28(5):e13082.

15. Niu L, Liang Y, Niu M. Factors influencing fear of cancer recurrence in patients with breast cancer: evidence from a survey in Yancheng, China. J Obstet Gynaecol Res. 2019:45(7):1319-27.

16. Waters EA, Liu Y, Schootman M, Jeffe DB. Worry about cancer progression and low perceived social support: Implications for quality of life among early-stage breast cancer patients. Ann Behav Med. 2013:45(1):57-68.

17. Dunn LB, Langford DJ, Paul SM, Berman MB, Shumay DM, Kober K, et al. Trajectories of fear of recurrence in women with breast cancer. Support Care Cancer. 2015;23(7):2033-43.

18. Firouzbakht M, Hajian-Tilaki K, Moslemi D. Analysis of quality of life in breast cancer survivors using structural equation modelling: the role of spirituality, social support and psychological well-being. Int Health. 2020;12(4):354-63.

19. Thoits PA. Mechanisms linking social ties and support to physical and mental health. J Health Soc Behav. 2011;52(2):145-61.

20. Romeo A, Di Tella M, Ghiggia A, Tesio V, Gasparetto E, Stanizzo MR, et al. The traumatic experience of breast cancer: which factors can relate to the post-traumatic outcomes? Front Psychol. 2019;10:891.

21. You J, Lu Q. Social constraints and quality of life among Chinesespeaking breast cancer survivors: a mediation model. Qual Life Res. 2014:23(9):2577-84

22. Li CC, Chen ML, Chang TC, Chou HH, Chen MY. Social support buffers the effect of self-esteem on quality of life of early-stage cervical cancer survivors in Taiwan. Eur J Oncol Nurs. 2015;19(5):486-94.

23. Sauer C, Weis J, Faller H, Junne F, Honig K, Bergelt C, et al. Impact of social support on psychosocial symptoms and quality of life in cancer patients: results of a multilevel model approach from a longitudinal multicenter study. Acta Oncol. 2019;58(9):1298-306.

24. Koch-Gallenkamp L, Bertram H, Eberle A, Holleczek B, Schmid-Hopfner S, Waldmann $A$, et al. Fear of recurrence in long-term cancer survivors-do cancer type, sex, time since diagnosis, and social support matter? Health Psychol. 2016;35(12):1329-33.

25. Hsiao FH, Klimidis S, Minas H, Tan ES. Cultural attribution of mental health suffering in Chinese societies: the views of Chinese patients with mental illness and their caregivers. J Clin Nurs. 2006;15(8):998-1006.

26. Oven Ustaalioglu B, Acar E, Caliskan M. The predictive factors for perceived social support among cancer patients and caregiver burden of their family caregivers in Turkish population. Int J Psychiatry Clin Pract. 2018:22(1):63-9.

27. Nissen KG, Trevino K, Lange T, Prigerson HG. Family relationships and psychosocial dysfunction among family caregivers of patients with advanced cancer. J Pain Symptom Manag. 2016;52(6):841-9.

28. Toledo G, Ochoa CY, Farias AJ. Exploring the role of social support and adjuvant endocrine therapy use among breast cancer survivors. Support Care Cancer. 2020;28(1):271-8.

29. Leung J, Pachana NA, McLaughlin D. Social support and health-related quality of life in women with breast cancer: a longitudinal study. Psychooncology. 2014;23(9):1014-20.

30. Yu Y, Sherman KA. Communication avoidance, coping and psychological distress of women with breast cancer. J Behav Med. 2015:38(3):565-77. 
31. Celik GK, Cakir H, Kut E. Mediating role of social support in resilience and quality of life in patients with breast cancer: structural equation model analysis. Asia Pac J Oncol Nurs. 2021;8(1):86-93.

32. Manning-Walsh J. Social support as a mediator between symptom distress and quality of life in women with breast cancer. J Obstet Gynecol Neonatal Nurs. 2005;34(4):482-93.

33. Li MC, Cheng HL. Fear of cancer recurrence, supportive care needs, and the utilization of psychosocial services in cancer survivors: a cross-sectional survey in Hong Kong. Psychooncology. 2020;30(4):602-13.

34. Fan L, Strasser-Weippl K, Li J-J, St Louis J, Finkelstein DM, Yu K-D, et al. Breast cancer in China. Lancet Oncol. 2014;15(7):e279-89.

35. Chen SQ, Liu JE, Zhang ZX, Li Z. Self-acceptance and associated factors among Chinese women with breast cancer. J Clin Nurs. 2017;26(11-12):1516-23.

36. Wan C, Zhang D, Yang Z, Tu X, Tang W, Feng C, et al. Validation of the simplified Chinese version of the FACT-B for measuring quality of life for patients with breast cancer. Breast Cancer Res Treat. 2007;106(3):413-8.

37. Brady MJ, Cella DF, Mo F, Bonomi AE, Tulsky DS, Lloyd SR, et al. Reliability and validity of the Functional Assessment of Cancer Therapy-Breast quality-of-life instrument. J Clin Oncol. 1997:15(3):974-86.

38. Mehnert A, Herschbach P, Berg P, Henrich G, Koch U. Fear of progression in breast cancer patients-validation of the short form of the Fear of Progression Questionnaire (FoP-Q-SF). Z Psychosom Med Psychother. 2006:52(3):274-88.

39. Wu QYZ. Li L Reliability and validity of Chinese version of fear of progression questionnaire-short form for cancer patients. Chinese J Nurs. 2015:50(12):1515-9 (article in Chinese).

40. Zimet GD, Powell SS, Farley GK, Werkman S, Berkoff KA. Psychometric characteristics of the Multidimensional Scale of Perceived Social Support. J Pers Assess. 1990;55(3-4):610-7.

41. Wang F, Liu J, Liu L, Wang F, Ma Z, Gao D, et al. The status and correlates of depression and anxiety among breast-cancer survivors in Eastern China: a population-based, cross-sectional case-control study. BMC Public Health. 2014;14(1):326

42. Obrien RM. A caution regarding rules of thumb for variance inflation factors. Qual Quantity. 2007;41(5):673-90.

43. Preacher KJ, Hayes AF. Asymptotic and resampling strategies for assessing and comparing indirect effects in multiple mediator models. Behav Res Methods. 2008;40(3):879-91.

44. An Y, Fu G, Yuan G. Quality of life in patients with breast cancer: the influence of family caregiver's burden and the mediation of patient's anxiety and depression. J Nerv Ment Dis. 2019:207(11):921-6.

45. Milbury K, Kavanagh A, Meng Z, Chen Z, Chandwani KD, Garcia K, et al. Depressive symptoms and positive affect in Chinese and United States breast cancer survivors: a cross-cultural comparison. Support Care Cancer. 2017;25(7):2103-9.

46. Matthies LM, Taran FA, Keilmann L, Schneeweiss A, Simoes E, Hartkopf AD, et al. An electronic patient-reported outcome tool for the FACT-B (Functional Assessment of Cancer Therapy-Breast) questionnaire for measuring the health-related quality of life in patients with breast cancer: reliability study. J Med Internet Res. 2019;21(1):e10004.
47. Park JH, Jung YS, Jung YM, Bae SH. The role of depression in the relationship between cognitive decline and quality of life among breast cancer patients. Support Care Cancer. 2019;27(7):2707-14.

48. Lam WW, Au AH, Wong JH, Lehmann C, Koch U, Fielding R, et al. Unmet supportive care needs: a cross-cultural comparison between Hong Kong Chinese and German Caucasian women with breast cancer. Breast Cancer Res Treat. 2011:130(2):531-41.

49. Lee S, Chen L, Ma GX, Fang CY, Oh Y, Scully L. Challenges and needs of Chinese and Korean American breast cancer survivors: in-Depth Interviews. N Am J Med Sci (Boston). 2013;6(1):1-8.

50. Spatuzzi R, Vespa A, Lorenzi P, Miccinesi G, Ricciuti M, Cifarelli W, et al. Evaluation of social support, quality of life, and body image in women with breast cancer. Breast Care (Basel). 2016;11(1):28-32.

51. Karam AK. Breast cancer posttreatment surveillance: diagnosis and management of recurrent disease. Clin Obstet Gynecol. 2011;54(1):157-63.

52. Simonelli LE, Siegel SD, Duffy NM. Fear of cancer recurrence: a theoretical review and its relevance for clinical presentation and management. Psychooncology. 2017;26(10):1444-54.

53. Berg CJ, Vanderpool RC, Getachew B, Payne JB, Johnson MF, Sandridge $Y$, et al. A hope-based intervention to address disrupted goal pursuits and quality of life among young adult cancer survivors. J Cancer Educ. 2020;35(6):1158-69.

54. Gotze H, Taubenheim S, Dietz A, Lordick F, Mehnert-Theuerkauf A. Fear of cancer recurrence across the survivorship trajectory: results from a survey of adult long-term cancer survivors. Psychooncology. 2019;28(10):2033-41.

55. Crist JV, Grunfeld EA. Factors reported to influence fear of recurrence in cancer patients: a systematic review. Psychooncology. 2013;22(5):978-86.

56. Sultan S, Fisher DA, Voils Cl, Kinney AY, Sandler RS, Provenzale D. Impact of functional support on health-related quality of life in patients with colorectal cancer. Cancer. 2004:101(12):2737-43.

57. Acquati C, Miyawaki CE, Lu Q. Post-traumatic stress symptoms and social constraints in the communication with family caregivers among Chinese-speaking breast cancer survivors. Support Care Cancer. 2019:28(9):4115-22.

58. Lim JW, Shon EJ, Paek M, Daly B. The dyadic effects of coping and resilience on psychological distress for cancer survivor couples. Support Care Cancer. 2014;22(12):3209-17.

59. Classen CC, Kraemer HC, Blasey C, Giese-Davis J, Koopman C, Palesh OG, et al. Supportive-expressive group therapy for primary breast cancer patients: a randomized prospective multicenter trial. Psychooncology. 2008;17(5):438-47.

60. Kissane DW, Grabsch B, Clarke DM, Smith GC, Love AW, Bloch S, et al. Supportive-expressive group therapy for women with metastatic breast cancer: survival and psychosocial outcome from a randomized controlled trial. Psychooncology. 2007;16(4):277-86.

\section{Publisher's Note}

Springer Nature remains neutral with regard to jurisdictional claims in published maps and institutional affiliations.

\footnotetext{
Ready to submit your research? Choose BMC and benefit from:

- fast, convenient online submission

- thorough peer review by experienced researchers in your field

- rapid publication on acceptance

- support for research data, including large and complex data types

- gold Open Access which fosters wider collaboration and increased citations

- maximum visibility for your research: over 100M website views per year
}

At BMC, research is always in progress.

Learn more biomedcentral.com/submissions 